made to visit bealth resorts, for a condition which neither indicates heart failure in the present nor its likelihood in the future. The fact that heart failure did not arise has probably been attributed to the precautionary measures. From this comes the belief in the efficacy of many of the drugs and methods in use to-day. When many of these vaunted remedies are carefully investigated, their uselessness becomes evident. Take, for instance, the present-day belief in the efficacy of strychnine on the heart, a belief held not only by a great many physicians, but which exercises an almost superstitious regard in the mind of many of our surgicel brethren, in whom the belief is so deeply rooted that they will not undertake an operation without the preliminary ceremonial rite of a hypodermic injection of strychnine. I have sought in vain for the slightest evidence of the effecr of medicinal doses of strychnine npon the heart, and have searched the literature on the subject and have not found one single reliable instance demonstrating the effects of medicinal doses. Pharmacologists have repeatedly examined with the minutest care the effects of medicinal doses of strychnine upon the heart in experiment, and have failed to obtain a result of any kind. So it is with a great many other drugs and methods, with the unfortunate result that the effects of drugs that are really of service are never properly appreciated.

We might not care so much for these erroneous beliefs were it not that they blind the profeseion to the great want of suitable agents in treating real and serious affections of the heart. There are many conditions in which rest alone fails to benefit the heart, as when the heart is invaded by a toxin, or rendered irritable from some lesion in the heart itself, or when the ventricle in heart-block contracts so seldom as to endanger life. For these and many other conditions we are absolutely without any means of meeting the impending and actual danger, and yet we are kept in ignorance of this fact becanse writers pour forth a stream of remedies for any and every kind of heart trouble. Were we more alive to our own limitations we should be more industrious in the search for real and valuable remedies.

\section{THE SURGICAL TREATMENT OF CHRONIC COLITIS.*}

BY D'ARCY POWER, F.R.C.S.ENG.,

SURGEON TO, $\triangle$ ND LECTORER ON SURGERY AT, ST. BARTHOLOMEW'S HOSPITAL.

Chronic colitis, like many other clinical terms, includes different conditions under a single heading. There is a colitis due to simple irritation of the bowel, a colitis due to protozoal infection, and another form due to bacteria. The surgeon, however, bas no need of an eiaborate classification, for he is called upon to treat only two classes of cases: those in which a cause can be found, and those where the patient is suffering from toxaemia due to the absorption of septic products from an ulcerating bowel, the cause of the ulceration being unknown.

The two conditions are liable to be mistaken in the early stages, and it is important, therefore, to make a thorough and methodical examination as soon as possible. A correct diagnosis cannot usually bo arrived at in the out-patient room of a hospital or in the consulting room of the surgeon. The patient should, therefore, be kept in bed a day or two before any examination is made, and should be placed in charge of a competent nurse. The bowels should be empticd and cleansed by simple enemata and by irriga. tion with unirritating lotions. When this has been done thoroughly, digital examination, followed by the carefal use of a sigmoidoscope, will often reveal a cause if the inflammation is limited to the rectum or the lower part of the sigmoid flexure. Abdominal palpation maj give a clue when the cause is situated in the colon at a greater distance from the anue. Such a local examination will show that Eome cases of chronic inflammation of the bowel are due to gross causes. The colon may be irritated by the long.continued presence of scybala which have become packed away in the sacculi of the intestine, leaving the lumen free. The patient thus has a daily action of the bowels in spite of the impaction of freces, and * Remarks introductory to a discussion on chronic colitis at the
Harveian Society of London (see p. 874). the cause is only recognized when the irrigation brings away masses of foul-smelling faeces, and the irritation sudsides. Local irritation, too, may be due to the presence of a polypus or of an unsuspected cancer of the rectum; more rarely it may be due to actinomycosis, to glanders, to tabercle, to some strain of pnenmococcus, to gonorrhoea, or even to syphilis. I have also seen it in a fow cases of pericolitis where an abscess, formed outside the bowel, has afterwards burst into its lumen.

When these causes have been eliminated there remains a large class of cases which are grouped under the comprehensive heading of "ulcerative colitis," although there is no doubt that several subclasses of the disease exist. In these cases the large intestine may be ulcerated locally, or the inflammation may extend throughout its whole extent. The lesion is chronic, destructive and generally extensive. It rarely leads to perforation of the bowel; it is hardly ever associated with abscess of the liver; it kills by toxaemia. It occurs equally in men and in women, an? although it occurs in epidemics, it is usually sporadic, as we see it in private and in hospital prastice. The number of cases, I think, is increasing, but this may perhaps be due to the fact that $I$ have been interested in the subject, and more cases therefore have been sent to me.

Local examination of a case of ulcerative colitis reveals no gross cause, and the inflammation requires for its investigation all the resources of modern bacteriology, and. even then the pathologist may have to confess that he is without any clue to its nature.

During the last three jears I have had ten cases of ulcerative colitis under my care, two of whom died. Here in brief is the record of a case, for the notes of which I am indebted to Dr. Ogier Ward, who was fortunate enough to. have followed it from beginning to end:

A gentleman aged 30 first came under observation on Ootober 5th, 19c4, suffering from constipation. He said that his bowels had always been obstinate, but that they had become worse lately. Diet and the use of glycerine enemats relieved him until June 9th 1905, use of glycerine enemats relieved him last three weeks his bowels had again become irregular, and last three weeks his bowels bad again become irregular, and
that he had seen blood in his stools. Examination showed that he was suffering from a flssure of the anus. The fissure was tonched with caustic, and a week later the patient reported that he had not seen any more blood, but he was found to have four ulcers extending radially from the margin of the anus. Simple treatment caused the ulcers to heal, and the patient remained well until August 20th, 1906, when he applied for the relief of a pustular eruption on his hands which be thought he had contracted in the pursuit of his occupation as a buyer of fars. Rectal examination showed that he had a tiny fissure of the skin in the immediate neighbourhood of the anus.

He did not present himself again until March 10th, 1910, when an examination showed that the flssures were still present. There was no pain when the bowels were relieved, but blood spattered the pan of the closet. His bowels were very irregular, and the patient complained that when he had emptied them after breakfast it was often necessary for him to do so again within twenty minutes, the second motion being solid or liquid. He had slept well until the last week, when his sleep had been disturbed by the necessity of getting up to relieve his bowels. For instance, on the previous night he had a good stool at 2 a.m., but at 3 a.m. he was obliged to rise again to pass some watery stuff. He had lost his appetite and so much of his former vigour that he was unable to continue his business. It was noted that his teeth were very foul, and rectal examination showed that he had two amall piles. On March 2nd the patient had passed blood and mucus three or four times by the bowel, and there was some spasm of the anus. The pulse was 105 and the temperature $99^{\circ} \mathrm{F}$. On April 7 th a well-marked fissure of the anus had formed, and there was some eversion of the margin, as though the external sphincter had lost its tone. The gums and mouth were in a much more healthy condition, and the patient was able to use a toothbrush. On April 18th the patient wrote complaining of "rheumatism" on the right side, and when he was seen on A pril 25th it was obvious that he was extremely ill was seen on A.pril 25 th it was obvious that he was extremely ill.
His pulse wa.3 120 , his temperature was $103.3^{\circ} \mathrm{F}$., and he bad His pulse was 120 , his temperature was $103.3^{\circ} \mathrm{F}$., and he bad
had a rigor. He passed bis motions frequently, the stools being had a rigor. He passed his motions frequently, the stools being was swollen and red, and there was pain along the right sartorius muscle.

I saw him on April 28th, and found that he was passing stools containing blood clots and that he had a chronic ulceration extending from the margin of the anus upwards into the bowel On May lith he was seen by Dr. Hale White, who recommended that an appendicostomy should be done to ensure a better irrigation of the bowel, as it was clear that he was suffering from ulcerative colitis associated with profound toxaemis. This operation I performed on May 12th, and the bowel was washed out, whilst the patient was still ueder the anaestbetic, with three pints of hot ealine solution. This was repeated daily, and the report states that on May 15th there was no longer any blood, pus, or mucus. The patient remained very ill, however, and he was given a vaccine prepared from his own pus. The 
quantity varied from 5 to 10 millions, and the injections were made on May 15th, May 18th, May 24th, May 3lst, and June 7th.

A little pas and blood appeared from time to time in the discharge from the bowel, which never became so offensive as it was before the appendicostomy. The temperature, which had oscillated widely between $102^{\circ} \mathrm{F}$. and $98^{\circ} \mathrm{F}$., began to show smaller excursions about the beginning of June, and there was no rigor after the operation. The patient left the nursing home on Angust 15th, but it was not notil Beptember 13th that he was able to be carried out into his garden, nor antil the middle of November that he conld stand without support. He then began to incresse in weight stesdily from 6 st. $4 \mathrm{lb}$. on Ootober 23rd to 8 st. $4 \frac{1}{3} \mathrm{lb}$. on December 19th. By this time the swelling of his wrists had subsided. On January 11th, 1911, his weight had increased to 8 st. $9 \mathrm{lb}$., but he had experienced a olight relapse, as his wrists had again become puffy, and there was a return of the discharge from the bowel. The note adds that the patient had suffered similar relapses on previous occasions, and that they seemed to follow a low days after any extra effort or mental excitement.

The history of this case is singularly complete, because Dr. Ogies Ward was able to follow it from its very begin. ning to convalescence. It shows several of the features which I have found to be common in ulcerative colitis. A gradual onset, marked by a weakness of the rectal mucous mombrane, followed by chronic irritation, leading to incressed secretion of mucus, and by a desire to go to stool. The irritation passes on slowly to nlceration, marked by the appearance of blood, pus, and offensive stools. Absorption of these inflammatory products produces a state of profound toxaemia, from which the patient may be unable to recover.

The actual cause of the ulceration is nnknown, although in several of my cases it has followed parturition, piles, fistula, and fissure. The diagnosis in the later stages is esey, but I find that the medical practitioner is apt to think more lightly of the condition than is warranted by the severity of the disease. The ulceration begins in sidiously and with so little pain that the pationt only thinks of it as an attack of diarrhoea lasting longer than ueuel. The patient feels ill, it is true, but the languor is a tributed, naturally enough, to the disturbance of the bow ls. Even in advanced cases when the onset has been rapid the facial expression is no guide to the local condition, and the friends, therefore, do not become alarmed. This was well exemplified in one of my hospital cases, when it occurred to some of my dressers to ask whether the patient was not a phenomenally lazy person who was making the most of an attack of diarrhoea lasting longer than usual. I asked whether it was our custom to take cases of diarrhoea into a surgical ward. I showed them the patulous anus from which a foul. smelling mucus issued almost continuously, and a few weeks later they were able to see the ulcerated mucous membrane of the colon at the post mortem examination.

As a result of this failure to appreciate the severity of the disease it often happens that milder remedies are emplojed long after the time when they should have been abandoned. Castor oil and irrigation of the rectum by means of a Higginson's syringe are excellent methods of treatment at first, but more heroic means must be adopted if the conditions do not improve quickly. Foremost amongst these comes vaccine-therapy, the vaccine being made from the particular strain of micro-organism which is causing the inflammation. Death from toxaemia is the great danger of the disease, and if the patient is to be rendered immune the earlier the process is begun the more likely are the results to be satisfactory. It is advisable, therefore, to call in the bacteriologist as soon as possible. The surgeon may have to follow. It is clear to most of us that the large intestine cannot be cleansed in its whole extent by simple irrigation from the anus. It is also known from post-mortem examinations in only too many cases of ulcerative colitis that any part or even the whole of the large intestine may be ulcerated. The products of the alceration are very abundant, and their absorption is on $\theta$ of the most serious dangers of the disease. It is important, therefore, to cleanse the bowel and to keep it free from putrefying products. Drainage bbrough the appendix enables this to be done in the most satisfactory manner. The operation of appendicostomy is not so serious as that required for removal of the appendix during the quiet stage. It is very effective, and the fistula can afterwards be closed without trouble; indeed, in some of my cases the difficalty has been to prevent spontaneous closure. On the other hand, it must be clearly understood that appendicostomy will not cure ulcerative colitis, and the friends of the patient should have this clearly explained to them at the time of the operation, or they will be disappointed. The object of the operation is to keep the bowel clean and to prevent the absorption of toxic products. The nlcerative process continues nutil the patient becomes immune either by a natural process or by artificial means. A ppendicostomy, therefore, prolongs the life of the patient, and thas gives him a better opportanity to be cured. In the cases which have come under my own observation the first effect of appendicostomy has been a material improvtment in the condition of the patient, even in the most advanced cases. The temperature falls, the appetite returns, and may remain good permanently. The improvement in the general condition, however, is not maintained in its full extent, and a relapse occurs after a week or two. These relapees are a canse of great anxiety, but, so far as I have seen them, they have only been temporary, and the net result of the operation has been a slow but interrupted progress to recovery after months of illness.

I have tried many different drugs as local applications in these difficult cases of ulcerative colitis. Caibolic acid in all its forme, and however disguised, has caused carbol uria so often that I have ceased to use it. Bismuth sali. cylate, percbloride of mercury, biniodide of mercury and boric acid cansed irritation in the earlier stages and were discontinned. Bismuth carbonate (15 grains to 1 pint), potassium permanganato (1 in 30,000 ), and allmatein, which is haomatoxylon acted on by formal debyde (40 grains to 1 pint), proved most nseful, and were soothing. In the later stages of the disesse irrigation with perchloride of mercury $(1$ in 20,000$)$, zine sulphate (4 drachms to 3 pints), and silver nitrate in the strength of 5 to $\mathbf{1 0}$ grains to the pint of sterilized water gave the best results when they were used alternately. Ionized irrigations were employed on several occasions, but I could not satiofy myself that they were followed by any marked improvement. Chlorodyne was always useful when an anodyne was required, and it never seemed to lose its effect.

\section{THE USE OF VACCINES IN ACUTE MASTITIS.}

$\mathrm{BY}$

T. H. C. BENIANS, M.R.C.S.ENG., L.R C.P.LoND, JUNIOR ASSIBTANT, INOOULATION DEPARTMENT, LONDON HOSPITAL.

(From the London Hospital Bacteriological Laboratory : Dr. W. Bulloch.)

A considerable amount of work has been carried out on the etiology of acute mastitis, but, with the exception of a fow isolated cases, little seems to bave been done to apply the knowledge so gained by resorting to specific therapy. The cause of this cannot be that acute mastitis is always of short duration, with rapid recovery. A visit to any large out-patient department will show cases of chronic sinuses of breast which obstinately refuse to close up, and remain discharging for months and even years. By a timely use of vaccines in the more acute stages these chronic cases might be prevented from occurring. It is not suggested that inoculation treatment can replace surgery. For reasons I shall give later, it is seldom this most desirable end can be attained. Knowing, however, the specific nature of the disease, it is only rational that we should attempt to increase the resistance of the patient against the particular organism invading the tissues.

Bacteriology and Mode of Infretion.

The infective nature of this condition being an esta. blished fact, it remains to discuss the nature of the organisms and their mode of entrance into the breast. These two matters are of fundamental importance in the question of treatment of vaccines.

From an examination of the pus it has been found that almost any of the common pathogenic bacteria may be present. In a very large proportion of cases, however, Staphylococcus aureus is obtained in pure culture. In a much smaller number of cases streptococci have been found, either together with Staphylococcus aureus or, more rarely, in pure culture. Staphylococcus albus is 